\title{
Work and wellbeing-related consequences of different return-to- work pathways of persons with spinal cord injury living in Switzerland
}

\author{
Bruno Trezzini $\mathbb{\Phi}^{1,2} \cdot$ Urban Schwegler $\mathbb{1}^{1,2} \cdot$ Jan D. Reinhardt $\mathbb{D}^{1,2,3}$ for the SwiSCl Study Group
}

Received: 9 November 2017 / Revised: 23 March 2018 / Accepted: 3 April 2018 / Published online: 12 June 2018

(c) International Spinal Cord Society 2018

\begin{abstract}
Study design Observational study based on the 2012 community survey of the Swiss Spinal Cord Injury Cohort Study (SwiSCI).

Objectives To investigate work and wellbeing-related consequences of different return-to-work (RTW) pathways after SCI. Setting Community-based.

Methods Using a subsample of 243 SwiSCI participants, we determined whether a respondent had returned to the pre-injury employer, started with a new employer or had not returned to gainful employment post-SCI. For each pathway, descriptive statistics were provided and work and wellbeing-related consequences were examined with regression analyses.

Results One hundred eleven (45.7\%) participants had returned to their pre-injury employer, $80(32.9 \%)$ had changed employers and $52(21.4 \%)$ had never returned to paid work post-SCI. Although returning to the pre-injury employer was associated with a shorter RTW time and a higher current weekly work time compared with starting work with a new employer, no significant differences were found with regard to current employment status and post-SCI work duration. Concerning wellbeing-related outcomes (i.e., income, quality of life and life satisfaction), the two pathways did not differ.

Conclusions Although lasting RTW had beneficial wellbeing outcomes, the specific pathway initially taken (i.e., pre-injury vs. new employer) appeared less crucial. Although the two pathways seem equally viable, longitudinal data are required to corroborate the present findings, and future research needs to clarify the role of the client triage system and of vocational rehabilitation practices with regard to person-job match and its impact on job satisfaction and job performance.
\end{abstract}

\section{Introduction}

Return to work (RTW) and lasting employment after a spinal cord injury (SCI) are important goals from the perspective of the individual as well as society [1]. For society, it is important not only for economic reasons [2], but also owing to the obligation to provide fair employment

Bruno Trezzini

bruno.trezzini@paraplegie.ch

1 Swiss Paraplegic Research, Nottwil, Switzerland

2 Department of Health Sciences and Health Policy, University of Lucerne, Lucerne, Switzerland

3 Institute for Disaster Management and Reconstruction, Sichuan University and Hong Kong Polytechnic University, Hong Kong, China opportunities for people with disabilities [3]. From the individual's perspective, being able to work is associated with multiple beneficial outcomes beyond providing an income [4] such as adjustment to SCI [5], social contact and recognition [6], life satisfaction and wellbeing [7].

RTW and labor market participation rates of individuals with SCI vary widely across countries [1]. For Switzerland, Marti et al. [8] found that $87.4 \%$ of the study participants of working age at the onset of SCI had worked at some time after their injury, but only $63.8 \%$ were gainfully employed at the time of the study. A more recent survey indicated that in 2012 the employment rate was 53.4\%, about $30 \%$ points lower than in the Swiss general population [9]. Swiss disability insurance schemes allow for partial disability benefits and provide financial support for assistive devices, workplace accommodations, and vocational retraining [10]. There are, however, no legal obligations for employers to accommodate persons with a 
disability. Employees unable to work due to sickness or an accident can be dismissed after a protection period of 180 days [11].

Returning to their pre-injury employer (either in the same or an adapted job) or starting with a new employer (by changing jobs and/or undergoing vocational retraining) are the two major avenues back into paid work for persons who were employed at SCI onset. Generally, vocational rehabilitation practitioners and researchers consider returning to one's pre-injury employer the obvious and preferable pathway because it is expected to increase the chances of a speedy RTW and lasting employment success [12-17]. Presumably, disability insurance authorities also prefer this pathway because it saves retraining costs in the short run. However, it is unclear whether retraining and starting with a new employer may not be more beneficial for sustained employment in the long run.

Qualitative research provides some evidence for the positive role that returning to one's former employer plays for successful re-employment post-SCI [13], giving rise to the expectation that policies that promote RTW with the pre-injury employer would likely increase the employment rates of persons with SCI [14]. Furthermore, quantitative analyses of time to RTW found that returning to the pre-injury employer was associated with a shorter time interval as compared with starting with a new employer [15-17]. However, preliminary evidence also suggests that people who start work with a new employer tend to be more satisfied with their job and less often have reduced working hours than those who return to the pre-injury employer [18].

Hence, whether and to what extent the expected benefits of initially returning to the pre-injury employer do materialize in the short and long term needs further scrutiny. In particular, it is important to understand whether people who return to work via different pathways are equally able to maintain their employment in the long run and whether there are any differential long-term wellbeing implications in terms of income, quality of life and life satisfaction. Apart from time to RTW, outcomes such as current employment status [19], current weekly work time [20], and post-SCI employment duration [21, 22] are of particular interest.

The aims of this study were:

(1) to determine the prevalence of three RTW pathways (i.e., never returned to paid work, returned to the preinjury employer, started with a new employer) and to describe associated sociodemographic and injuryrelated characteristics;

(2) to determine whether returning to the pre-injury employer had more beneficial outcomes as compared with starting work with a new employer.

\section{Methods}

\section{Participants}

We used data from a subsample of the Swiss Spinal Cord Injury Cohort Study (SwiSCI) 2012 community survey [23]. The target population of SwiSCI comprised all persons aged 16 years or older, diagnosed with a traumatic or nontraumatic SCI and living permanently in Switzerland [23]. Persons with congenital conditions, neurodegenerative disorders, and Guillain-Barré syndrome were excluded. The sampling frame drew on records from specialized SCI rehabilitation clinics and SCI-focused patient organizations. Of 1458 SwiSCI participants of employable age (ranging from 16 years to the Swiss statutory retirement age, i.e., 64 for women and 65 for men), 328 respondents had been randomly selected to answer additional questions related to their current and pre-SCI employment situation. Of those, the present analysis included 243 respondents who had been in paid work at the onset of SCI and eight respondents whose incomplete employment information was multiply imputed. Paid work was defined as any remunerative employment, including self-employed work and work as an apprentice and in sheltered workshops. The present study was covered by the ethics approval that SwiSCI had originally received from the competent Swiss authorities [23].

\section{Variables}

\section{RTW pathways}

We assigned participants to one of three RTW pathways: (1) never returned to paid work, (2) returned to pre-injury employer, and (3) started with a new employer.

\section{Outcomes}

We included the following work-related outcomes: (1) time to RTW, i.e., time between discharge from initial inpatient rehabilitation and first post-injury employment (months); (2) being in paid work at the time of the survey (yes/no); (3) weekly work time ratio, i.e., work time as a proportion of a standard 42-hour workweek (0-1); and (4) post-SCI work duration ratio, i.e., total time spent in gainful employment post-SCI as a proportion of time since SCI minus time to RTW (0-1), where total time in employment post-SCI was determined by asking participants how many years they were gainfully employed after discharge from initial inpatient rehabilitation. The wellbeing outcomes were: (1) household income (a seven-point scale ranging from < CHF 1500 to < CHF 9000); (2) quality of life (a single-item, five-point scale ranging from very bad to very good) [24]; and (3) life satisfaction (a single-item, 11-point 
scale ranging from completely dissatisfied to completely satisfied) [25].

\section{Covariates}

To control for potential confounders, we included gender, education (years), age at the time of the survey (years), and current civil status (married vs. unmarried) as sociodemographic control variables. In addition, we controlled for the following injury-related factors: age at SCI onset (years), time since SCI onset (months), type of SCI (paraplegic vs. tetraplegic), degree of SCI (complete vs. incomplete), and cause of SCI (traumatic vs. non-traumatic). We also included job satisfaction and job type at the time of SCI onset as job-related predictors. The former was evaluated with a single-item, five-point scale ranging from very unsatisfied to very satisfied. The latter was a dichotomous indicator variable (manual or physically more demanding vs. non-manual job) derived by analyzing respondents' answers to a free-text question regarding their pre-SCI job title and coding them to ISCO-08 occupational titles [26].

\section{Data analysis}

\section{Descriptive statistics}

All statistical analyses were conducted using Stata/MP 14.1 for Windows. Using only complete cases, a descriptive analysis of the characteristics of the study participants and the RTW pathways was performed. Differences in the characteristics of the three RTW pathways were examined using Pearson's $\chi^{2}$-test for categorical and analysis of variance (with Bonferroni correction for multiple comparisons) for continuous variables. Cumulative percentage distributions of the time elapsed between discharge from initial inpatient rehabilitation and start of the first paid job were plotted.

\section{Regression analyses}

We used multiple regression models to examine the unadjusted and adjusted impact of returning to one's pre-injury employer as compared with starting with a new employer. Since many standard diagnostic tests of model assumptions are not available for multiply imputed data sets, we performed such tests based on a single imputed dataset. For time to RTW, we applied a time-to-event analysis (Cox regression) [27]; to avoid dropping respondents who returned to work immediately after initial rehabilitation, i.e., RTW time $=0$, from the analysis, we added a small constant $(0.5)$ to the outcome variable. The model's proportional hazards assumption was satisfied (Schoenfeld test, $\chi^{2}$ $(10)=5.71, p=0.839)$. For current employment status, we used a binary logistic regression. For weekly work time ratio and post-SCI work duration ratio, which represent proportions that range from 0 to 1 , we performed fractional logistic regressions [28]. The linear regression assumptions of linearity, non-multicollinearity, homogeneity of variance as well as normality of the residuals were met for household income (without transformation) and life satisfaction (after taking squares to address left skewness). Finally, for quality of life we applied an ordinal logistic regression. After combining the two lowest of the five categories owing to sparseness, the proportional odds assumption was satisfied (Wald test, $\chi^{2}(20)=29.47, p=0.079$ ).

\section{Missing data}

To account for unit nonresponse, we used sampling weights in all regression analyses, calculated as the inverse of the propensity score of participation in the survey module on labor market participation [23]. We addressed item nonresponse by using multiple imputation by chained equations including all analysis variables followed by deletion of imputed outcomes [29]. Thirty imputed data sets were generated. The imputed data proved plausible and results based on complete case analyses were comparable to those using multiple imputation.

\section{Results}

\section{Respondent characteristics}

At the time of SCI onset, one person was employed in a sheltered workshop and 29 were undergoing apprenticeships, at the time of the survey the respective figures were 3 and 4 . Tables 1 and 2 provide an overview of selected sociodemographic and injury-related characteristics of the 243 study participants who had been gainfully employed at the time of SCI onset, as a whole and stratified by RTW pathways. Overall, participants were predominantly male (75.7\%), had an average age of 48.3 years, with 13.8 years of formal education, and $64.1 \%$ fell in one of the three middle household income groups. A majority of the respondents lived with paraplegia (70.7\%), 54.5\% reported an incomplete lesion, and $85.1 \%$ had sustained a traumatic SCI.

\section{Prevalence and characteristics of RTW pathways}

With regard to the prevalence and composition of the three different RTW pathways, Tables 1 and 2 indicate that 111 participants $(45.7 \%)$ had returned to their previous employers, $80(32.9 \%)$ had started to work for a new employer and $52(21.4 \%)$ had not returned to any paid work at the time of the survey. As shown in Table 1, the three 
Table 1 Characteristics of study participants and RTW pathways (independent variables)

\begin{tabular}{|c|c|c|c|c|c|c|c|c|c|}
\hline \multirow[b]{2}{*}{ Categorical variables [missing] } & \multicolumn{2}{|c|}{$\begin{array}{l}\text { Total }(n= \\
243)\end{array}$} & \multicolumn{2}{|c|}{$\begin{array}{l}\text { Never returned } \\
\text { to gainful } \\
\text { employment ( } n \\
=52)\end{array}$} & \multicolumn{2}{|c|}{$\begin{array}{l}\text { Returned to } \\
\text { pre-injury } \\
\text { employer ( } n= \\
111)\end{array}$} & \multicolumn{2}{|c|}{$\begin{array}{l}\text { Started with a } \\
\text { new employer } \\
(n=80)\end{array}$} & \multirow[b]{2}{*}{$p$} \\
\hline & $n$ & $\%$ & $n$ & $\%$ & $n$ & $\%$ & $n$ & $\%$ & \\
\hline \multicolumn{10}{|l|}{ Male [0] } \\
\hline No & 59 & 24.3 & 16 & 30.8 & 25 & 22.5 & 18 & 22.5 & \multirow[t]{2}{*}{0.469} \\
\hline Yes & 184 & 75.7 & 36 & 69.2 & 86 & 77.5 & 62 & 77.5 & \\
\hline \multicolumn{10}{|l|}{ Married or in civil union [0] } \\
\hline No & 112 & 46.1 & 23 & 44.2 & 44 & 39.6 & 45 & 56.3 & \multirow[t]{2}{*}{0.072} \\
\hline Yes & 131 & 53.9 & 29 & 55.8 & 67 & 60.4 & 35 & 43.8 & \\
\hline \multicolumn{10}{|c|}{ Manual/physically demanding pre-injury job [11] } \\
\hline No & 121 & 52.2 & 25 & 48.1 & 65 & 62.5 & 31 & 40.8 & \multirow[t]{2}{*}{0.013} \\
\hline Yes & 111 & 47.8 & 27 & 51.9 & 39 & 37.5 & 45 & 59.2 & \\
\hline \multicolumn{10}{|l|}{ SCI type: paraplegic [1] } \\
\hline No & 71 & 29.3 & 19 & 36.5 & 27 & 24.5 & 25 & 31.3 & \multirow[t]{2}{*}{0.264} \\
\hline Yes & 171 & 70.7 & 33 & 63.5 & 83 & 75.5 & 55 & 68.8 & \\
\hline \multicolumn{10}{|l|}{ SCI degree: complete [1] } \\
\hline No & 132 & 54.5 & 29 & 55.8 & 61 & 55.5 & 42 & 52.5 & \multirow[t]{2}{*}{0.903} \\
\hline Yes & 110 & 45.5 & 23 & 44.2 & 49 & 44.5 & 38 & 47.5 & \\
\hline \multicolumn{10}{|l|}{ SCI cause: traumatic [1] } \\
\hline No & 36 & 14.9 & 18 & 34.6 & 10 & 9.1 & 8 & 10.0 & \multirow[t]{2}{*}{$<0.001$} \\
\hline Yes & 206 & 85.1 & 34 & 65.4 & 100 & 90.9 & 72 & 90.0 & \\
\hline Continuous variables [missing] & Mean & SD & Mean & SD & Mean & $\mathrm{SD}$ & Mean & SD & $p$ \\
\hline Age at time of survey (years) [0] & 48.26 & 9.72 & 48.62 & 8.62 & 47.80 & 9.67 & 48.67 & 10.52 & 0.795 \\
\hline Age at SCI onset (years) [0] & 31.79 & 11.64 & 34.00 & 11.57 & 33.73 & 11.71 & 27.66 & 10.56 & 0.001 \\
\hline Time since injury (months) [0] & 197.03 & 136.21 & 174.44 & 115.75 & 167.47 & 120.64 & 252.74 & 152.37 & $<0.001$ \\
\hline Education (years) [5] & 13.78 & 2.97 & 12.98 & 2.89 & 14.14 & 2.71 & 13.77 & 3.29 & 0.079 \\
\hline
\end{tabular}

Notes: eight participants with multiply imputed employment information are not included; percentages exclude missing values $S D$ standard deviation
RTW pathways significantly differed with regard to age at SCI onset $(F(2,240)=7.95, p=0.001)$, time since SCI $(F(2,240)=10.83, p<0.001)$, SCI cause $\left(\chi^{2}(2)=20.41\right.$, $p<0.001)$ and type of pre-injury job $\left(\chi^{2}(2)=8.74, p=\right.$ $0.013)$. More specifically, the group of individuals who never returned to work post-SCI had a higher proportion of persons with non-traumatic SCI than the other two groups. The RTW pathway via the pre-injury employer was comprised of individuals who were comparatively less likely to have had a manual pre-injury job. Finally, the RTW pathway via a new employer had a much longer average time since injury than the two other groups, with further inspection revealing that $30 \%$ of participants assigned to this pathway had sustained their injury more than 30 years ago (as compared with less than $7 \%$ in the other groups); persons in this group also tended to have a lower mean age at SCI. As shown in Table 2, there were also significant differences among the three RTW pathways with regard to household income $\left(\chi^{2}(12)=29.04, p=0.004\right)$, quality of life $(F(2,239)=9.67, p<0.001)$ and life satisfaction $(F$ $(2,232)=12.74, p<0.001)$, with the group of persons who did not return to gainful employment always scoring lowest.

Figure 1 depicts the cumulative percentage distributions of the time to RTW after discharge for the pre-injury and new employer pathways. Eighty percent of the respondents who returned to their pre-injury employers did so within 7 months as compared with 28 months for the group of respondents who started to work for a new employer. Among the former, $48.6 \%$ returned immediately after completing initial inpatient rehabilitation as compared with $21.9 \%$ among the latter.

\section{Outcomes of RTW pathways}

\section{Work-related outcomes}

Model 1 in Table 3 indicates that, after controlling for other factors, persons who returned to their pre-injury employer 
Table 2 Characteristics of study participants and RTW pathways (dependent variables)

\begin{tabular}{|c|c|c|c|c|c|c|c|c|c|}
\hline \multirow[b]{2}{*}{ Categorical variables [missing] } & \multicolumn{2}{|c|}{$\begin{array}{l}\text { Total }(n= \\
243)\end{array}$} & \multicolumn{2}{|c|}{$\begin{array}{l}\text { Never } \\
\text { returned to } \\
\text { gainful } \\
\text { employment } \\
(n=52)\end{array}$} & \multicolumn{2}{|c|}{$\begin{array}{l}\text { Returned to } \\
\text { pre-injury } \\
\text { employer } \\
(n=111)\end{array}$} & \multicolumn{2}{|c|}{$\begin{array}{l}\text { Started with } \\
\text { a new } \\
\text { employer ( } n \\
=80)\end{array}$} & \multirow[b]{2}{*}{$p$} \\
\hline & $n$ & $\%$ & $n$ & $\%$ & $n$ & $\%$ & $n$ & $\%$ & \\
\hline \multicolumn{10}{|l|}{ Currently in paid work [0] } \\
\hline No & 78 & 32.1 & 52 & 100.0 & 13 & 11.7 & 13 & 16.3 & 0.367 \\
\hline Yes & 165 & 67.9 & 0 & 0 & 98 & 88.3 & 67 & 83.8 & \\
\hline \multicolumn{10}{|l|}{ Household income [6] } \\
\hline$<\mathrm{CHF} 1500$ & 3 & 1.3 & 2 & 3.8 & 1 & 0.9 & 0 & 0.0 & 0.004 \\
\hline CHF $1500-3000$ & 22 & 9.3 & 8 & 15.4 & 8 & 7.5 & 6 & 7.7 & \\
\hline CHF $3000-4500$ & 46 & 19.4 & 15 & 28.8 & 15 & 14.0 & 16 & 20.5 & \\
\hline CHF 4500-6000 & 52 & 21.9 & 13 & 25.0 & 17 & 15.9 & 22 & 28.2 & \\
\hline CHF 6000-7500 & 54 & 22.8 & 6 & 11.5 & 32 & 29.9 & 16 & 20.5 & \\
\hline CHF 7500-9000 & 37 & 15.6 & 5 & 9.6 & 17 & 15.9 & 15 & 19.2 & \\
\hline$>$ CHF 9000 & 23 & 9.7 & 3 & 5.8 & 17 & 15.9 & 3 & 3.8 & \\
\hline Continuous variables [missing] & Mean & SD & Mean & SD & Mean & SD & Mean & SD & $p$ \\
\hline Time to return to work (months) [11] & 12.55 & 31.92 & NA & NA & 3.75 & 5.54 & 25.45 & 46.94 & $<0.001$ \\
\hline Current weekly work time ratio [27] & 0.55 & 0.26 & NA & NA & 0.58 & 0.28 & 0.49 & 0.22 & 0.050 \\
\hline Post-SCI work duration ratio [14] & 0.85 & 0.24 & NA & NA & 0.89 & 0.20 & 0.79 & 0.28 & 0.008 \\
\hline Quality of life (range 1-5) [1] & 3.61 & 0.83 & 3.17 & 0.92 & 3.71 & 0.76 & 3.75 & 0.79 & $<0.001$ \\
\hline Life satisfaction (range $0-10$ ) [8] & 6.72 & 2.08 & 5.56 & 2.27 & 6.80 & 2.08 & 7.37 & 1.59 & $<0.001$ \\
\hline
\end{tabular}

Notes: eight participants with multiply imputed employment information are not included; percentages exclude missing values; SD, standard deviation; NA, not applicable; only the pre-injury employer and the new employer pathways were included in the tests for the four work-related outcomes

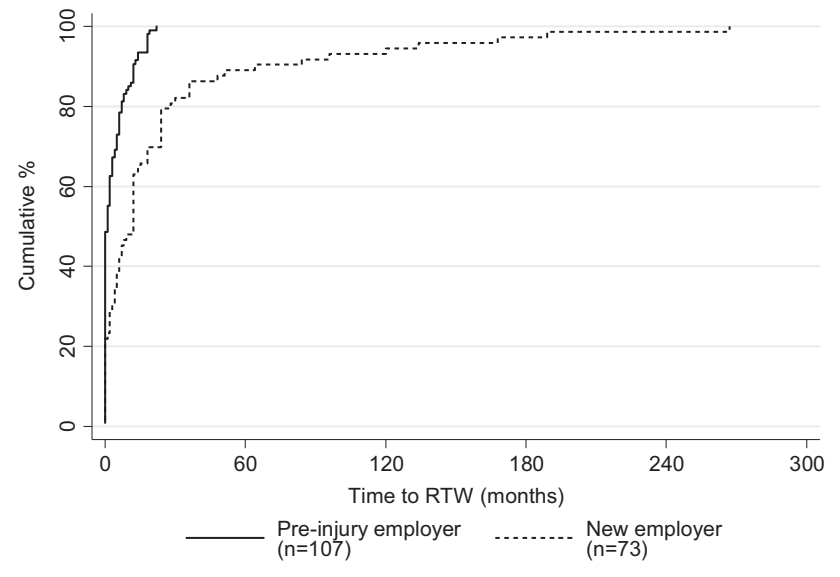

Fig. 1 Cumulative percentage distribution of time to RTW by type of post-SCI employer

did so faster than those respondents who started work with a new employer $(\mathrm{HR}=2.42, p<0.001 ; 95 \% \mathrm{CI}: 1.79-3.29)$. In addition, job satisfaction at time of SCI onset and male gender were associated with a shorter RTW time, whereas a traumatic SCI etiology prolonged it. With regard to current employment status (model 2 in Table 3), neither RTW pathway $(\mathrm{OR}=0.90 ; p=0.839 ; 95 \% \mathrm{CI}$ : $0.33-2.47)$ nor the other variables included in the model had a statistically significant impact. Weekly work time ratio was positively associated with RTW to pre-injury employer (coeff.(b) = $0.53 ; p=0.009 ; 95 \%$ CI: 0.13-0.93) and with being male, but negatively with a complete spinal cord lesion (model 3). Finally, whereas in the unadjusted analysis returning to the pre-injury employer was positively related to post-SCI work duration ratio $(\operatorname{coeff}(b)=0.70 ; p=0.013 ; 95 \%$ CI: 0.15-1.25), this effect became insignificant after controlling for the other covariates (coeff(b) $=0.52 ; p=0.093 ; 95 \%$ CI: -0.09-1.13) (model 4). Only being male showed a positive association.

\section{Wellbeing outcomes}

For all three wellbeing outcomes, i.e., household income, quality of life, and life satisfaction (models $1-3$ in Table 4), the RTW pathway variable did not exhibit any statistically significant associations, neither in the unadjusted nor the adjusted analyses. Regarding the other covariates, being employed at the time of the study, being married, being male, having more years of education and a longer time since SCI onset were all positively associated with household income. Conversely, a manual pre-injury job type had 


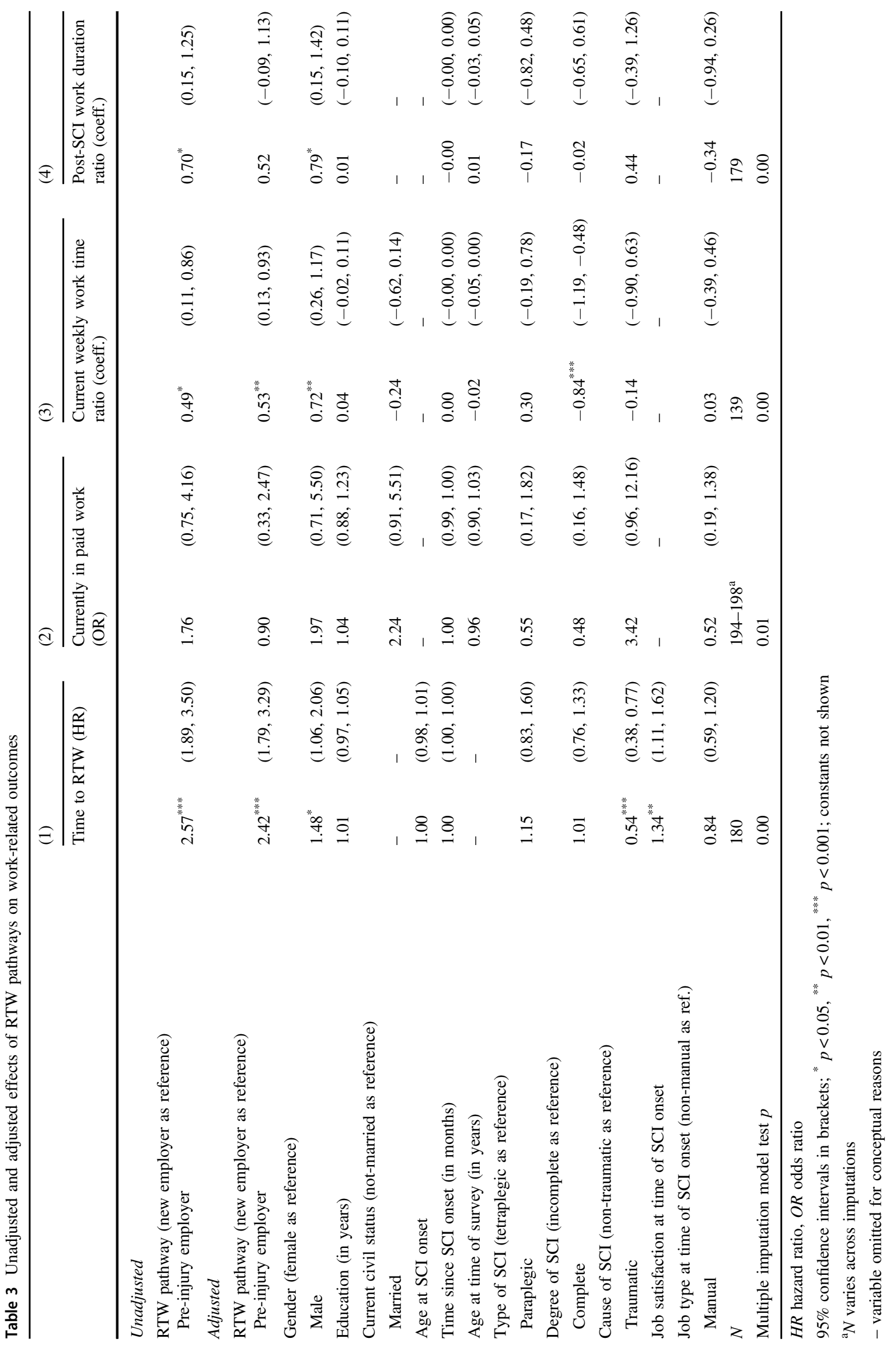


Table 4 Unadjusted and adjusted effects of RTW pathways on wellbeing outcomes

\begin{tabular}{llll}
$\begin{array}{l}\text { Household income level } \\
\text { (coeff.) }\end{array}$ & $\frac{(2)}{\text { Quality of life (OR) }}$ & Life satisfaction sq. (coeff.) \\
\hline
\end{tabular}

Unadjusted

RTW pathway (new employer as reference)

Pre-injury employer

\begin{tabular}{|c|c|c|c|c|c|}
\hline 0.34 & $(-0.09,0.77)$ & 1.01 & $(0.56,1.81)$ & -4.03 & $(-11.27,3.22)$ \\
\hline 0.16 & $(-0.23,0.54)$ & 0.95 & $(0.49,1.83)$ & -4.80 & $(-12.73,3.14)$ \\
\hline $0.80^{* * *}$ & $(0.39,1.22)$ & $3.83^{* *}$ & $(1.45,10.15)$ & 6.73 & $(-3.80,17.25)$ \\
\hline- & - & 1.00 & $(0.79,1.28)$ & 2.33 & $(-0.70,5.35)$ \\
\hline $0.52^{*}$ & $(0.05,0.98)$ & 1.31 & $(0.59,2.88)$ & -1.20 & $(-11.22,8.82)$ \\
\hline $0.07^{*}$ & $(0.01,0.14)$ & 0.99 & $(0.87,1.12)$ & -0.64 & $(-1.96,0.68)$ \\
\hline $0.71^{* *}$ & $(0.28,1.14)$ & 0.97 & $(0.53,1.76)$ & 1.34 & $(-6.28,8.97)$ \\
\hline $0.002^{*}$ & $(0.0003,0.0038)$ & 1.00 & $(1.00,1.00)$ & 0.01 & $(-0.02,0.04)$ \\
\hline-0.02 & $(-0.05,0.00)$ & 0.97 & $(0.94,1.01)$ & 0.10 & $(-0.32,0.53)$ \\
\hline-0.13 & $(-0.53,0.27)$ & 0.97 & $(0.51,1.87)$ & 1.39 & $(-7.36,10.13)$ \\
\hline-0.14 & $(-0.55,0.26)$ & 0.79 & $(0.42,1.46)$ & -5.83 & $(-14.21,2.56)$ \\
\hline-0.21 & $(-0.81,0.39)$ & 1.74 & $(0.70,4.30)$ & 9.81 & $(-3.66,23.29)$ \\
\hline$-0.94^{* * *}$ & $(-1.37,-0.52)$ & 0.52 & $(0.24,1.12)$ & 0.17 & $(-8.16,8.50)$ \\
\hline $188-191^{\mathrm{a}}$ & & $193-196^{a}$ & & $187-191^{\mathrm{a}}$ & \\
\hline 0.00 & & 0.04 & & 0.15 & \\
\hline
\end{tabular}

Adjusted

RTW pathway (new employer as reference)

Pre-injury employer

Work status (not employed as reference)

Employed

Household income

Gender (female as reference)

Male

Education (in years)

Current civil status (not-married as reference)

\section{Married}

Time since SCI onset (in months)

Age at time of survey (in years)

Type of SCI (tetraplegic as reference)

Paraplegic

Degree of SCI (incomplete as reference)

Complete

Cause of SCI (non-traumatic as reference)

Traumatic

Job type at time of SCI onset (non-manual as ref.)

Manual

$N$

Multiple imputation model test $p$

$O R$ odds ratio

$95 \%$ confidence intervals in brackets; ${ }^{*} p<0.05,{ }^{* *} p<0.01,{ }^{* * *} p<0.001$; constants not shown

${ }^{\mathrm{a}} \mathrm{N}$ varies across imputations

- variable omitted for conceptual reasons

a negative association with household income. For quality of life, only being employed showed a statistically significant positive association. None of the predictors had a significant effect on life satisfaction.

\section{Discussion}

This study examined the prevalence, characteristics, and outcomes of major RTW pathways of persons with SCI living in Switzerland. Results suggest that although sustained RTW, i.e., being employed at the time of the survey, had a beneficial impact on wellbeing-related outcomes such as income and quality of life, the RTW pathway that had initially been taken seemed less crucial. Returning to the pre-injury employer, as more than half of the participants who were gainfully employed at the time of their injury did, was associated with a shorter RTW time. Considering more long-term work-related outcomes, there were no significant differences between the pathways with regard to current employment status and total post-SCI employment duration. However, returning to the pre-injury employer was associated with a higher weekly work time ratio.

\section{Pathway prevalence and characteristics}

Our finding that a majority of the participants who returned to gainful employment did so with their pre-injury employer is comparable with the results of a Dutch study that found that whereas only $37 \%$ of their participants 
resumed gainful employment, $65 \%$ of them returned to the previous employer [30]. By contrast, for two US samples only $12 \%$ [31] and $17 \%$ [17] of the participants returned to their pre-injury job, which points to potential institutional and policy differences across countries. That more than one-fifth of the respondents who started work with a new employer did so immediately after initial inpatient rehabilitation may seem surprising, but could have been related to the fact that we also included persons in apprenticeships and sheltered workshops, for whom vocational counselors might have been able to arrange a seamless transition. Furthermore, although not directly comparable, Krause [17] also found that of the respondents who started work with a new employer $15 \%$ did so within a year since SCI onset.

Concerning pathway characteristics, a comparatively large proportion of persons who performed a manual preinjury job started work with a new employer. Manual jobs are often no longer feasible for the affected persons so that retraining and looking for a new employer become the likely avenue back to work. Although much lower than in the case of persons who started work with a new employer, it is also remarkable that a sizable proportion of the respondents who returned to the previous employer had a manual pre-injury job, suggesting that employers were willing and able to provide adapted or new jobs. Among the participants who had started work with a new employer, a large proportion fell into the highest time since injury group. This may be because in the past more people worked in manual jobs in the agricultural and manufacturing sector [32], where accommodations at the workplace might have been less feasible, making return to the pre-injury employer less likely.

\section{Pathway consequences}

\section{Work-related outcomes}

Our results regarding time to RTW are in line with previous research [15-17] reporting shorter time spans for persons who could return to their pre-injury employer and/or job as compared with starting with a new employer. This difference can most likely be attributed to the extra time needed for retraining and job search. Regarding current employment status, no statistically significant difference was found between returning to the pre-injury employer and starting with a new one, which puts Chapin and Kewman's [14] expectation that the promotion of RTW with former employers would likely improve employment rates for persons with SCI into perspective. Similar to our study, Krause et al. [19] did not find a significant association between return to the former company (either to the same or a different job) and current employment status. No difference between the two pathways was found with regard to post-SCI work time ratio. Taken together, these results might be seen as an indication that both pathways are equally viable RTW strategies in the long run. In terms of current weekly work time, and contradicting Schönherr et al. [18], returning to one's pre-injury employer was associated with a higher ratio, potentially reflecting an inverse relationship between the affected person's work incapacity and the pre-injury employer's willingness to take him or her back.

\section{Wellbeing-related outcomes}

Our results corroborate previous findings that gainful employment leads to higher income $[4,33]$ and quality of life [34]. Moreover, we found a positive, albeit statistically insignificant effect of employment status on life satisfaction, which is consistent with similar findings for a Canadian sample [35]. Beyond these results, our study adds the insight that there seem to be no major differences between returning to the pre-injury employer as compared with starting with a new one. With regard to household income, this result supports previous research, which also found that return to pre-injury employer (same or different job) was not associated with earnings of participants who were employed at the time of the survey [33].

\section{Implications for vocational rehabilitation practice}

The similarity in outcomes between returning to the preinjury employer and starting with a new one could be an indication that current vocational rehabilitation practices in Swiss SCI clinics are reasonably effective in distinguishing between those clients who, with accommodations, could successfully return to their pre-injury employer and those who might be better served by taking the RTW avenue that involves more fundamental job retraining. However, the fact that returning to the pre-injury employer did not lead to significantly better outcomes than starting with a new employer, could also point to potential shortcomings of current vocational rehabilitation practices. For example, although a speedy RTW appears desirable, a preoccupation with speed might overshadow other considerations in the occupational assessment process such as the actual match between a client's work interests and the adapted or newly created job that he or she will be returning to [36]. A matching job is likely to enhance a person's job satisfaction and job performance, potentially increasing the prospects of sustained employment [37, 38]. By contrast, a person-job mismatch might precipitate premature drop out of the labor market. Thus, it would seem prudent for vocational rehabilitation practitioners to pay particular attention to the assessment of person-job match also in the context of a 
speedy return to the previous employer, especially if the job content differs significantly from the pre-injury one.

\section{Limitations}

This study has a number of limitations. First, we used selfreported retrospective data based on a cross-sectional survey, which may have undermined the validity of our results owing to recall and selection biases. Second, we lacked information on crucial aspects such as health complications, personality traits, post-injury adjustment, job characteristics, and employer attitudes [39], potentially leading to model specification errors with regard to the various pathway outcomes. Third, we lacked information on the duration of initial inpatient rehabilitation and of periods when respondents were unavailable for work [40], which diminished the measurement accuracy of the post-SCI work duration ratio. Fourth, income was measured at the household and not the individual respondent level, which may have distorted income differentials. Fifth, quality of life and life satisfaction were ascertained with single-item measures potentially limiting their validity and reliability. Sixth, successful and sustainable RTW is highly context dependent and thus the study's findings cannot be readily generalized to other health conditions or countries with different disability policy and benefit systems. Finally, in order to more adequately trace the RTW and employment pathways of persons with SCI and to better capture the actual nature of the job a person returns to, longitudinal research designs and more fine-grained data collection are needed.

\section{Conclusions}

Although returning to the pre-injury employer as compared with starting with a new employer was advantageous in the short run in terms of a faster RTW, it was not associated with employment status in the long run. Moreover, although sustained post-injury RTW had beneficial wellbeing outcomes, the specific pathway taken appeared less crucial. Although the two RTW pathways may seem equally viable, future research needs to clarify the role of the client triage system and of vocational rehabilitation practices with regard to person-job match and its impact on job satisfaction and performance.

Acknowledgements We are grateful to all the participants of the SwiSCI survey for their time and effort spent in responding to the questions. We also thank Gerold Stucki for helpful feedback on an earlier version of this paper. We further thank the personnel of the SwiSCI study center and the SwiSCI Steering Committee whose members are: Xavier Jordan, Bertrand Léger (Clinique Romande de Réadaptation, Sion); Michael Baumberger, Hans Peter Gmünder (Swiss Paraplegic Center, Nottwil); Armin Curt, Martin Schubert (University Clinic Balgrist, Zürich); Margret Hund-Georgiadis, Kerstin Hug (REHAB Basel, Basel); Hans Georg Koch (Swiss Paraplegic
Association, Nottwil); Nadja Münzel (Parahelp, Nottwil); Hardy Landolt (Representative for persons with SCI, Glarus); Mirjam Brach, Gerold Stucki (Swiss Paraplegic Research, Nottwil); Martin Brinkhof, Christine Thyrian (SwiSCI Study Center at Swiss Paraplegic Research, Nottwil).

Author contributions BT was responsible for designing the study, conducting the data analysis, interpreting results and preparing the article. US and JR contributed to the data interpretation and article preparation.

Funding information The study was financed by Swiss Paraplegic Research within the framework of the Swiss Spinal Cord Injury Cohort Study (SwiSCI).

\section{Compliance with ethical standards}

Conflict of interest The authors declare that they have no conflict of interest.

\section{References}

1. Bickenbach J, Officer A, Shakespeare T, von Groote P (eds). International perspectives on spinal cord injury. Geneva: World Health Organization, International Spinal CordSociety; 2013.

2. García-Altés A, Pérez K, Novoa A, Suelves JM, Bernabeu M, Vidal J, et al. Spinal cord injury and traumatic brain injury: a costof-illness study. Neuroepidemiology. 2012;39:103-08.

3. United Nations. Convention on the Rights of Persons with Disabilities. Retrieved 20 January 2018, from http://www.ohchr.org/ EN/HRBodies/CRPD/Pages/ConventionRightsPersonsWithDisa bilities.aspx.

4. Ramakrishnan K, Loh SY, Omar Z. Earnings among people with spinal cord injury. Spinal Cord. 2011;49:986-9.

5. Krause JS. Adjustment to life after spinal cord injury: a comparison among three participant groups based on employment status. Rehabil Couns Bull. 1992;35:218-29.

6. Meade MA, Reed KS, Saunders LL, Krause JS. It's all of the above: benefits of working for individuals with spinal cord injury. Top Spinal Cord Inj Rehabil. 2015;21:1-9.

7. Hess D, Meade M, Forchheimer M, Tate D. Psychological wellbeing and intensity of employment in individuals with a spinal cord injury. Top Spinal Cord Inj Rehabil. 2004;9:1-10.

8. Marti A, Reinhardt JD, Graf S, Escorpizo R, Post MWM. To work or not to work: labour market participation of people with spinal cord injury living in Switzerland. Spinal Cord. 2012;50:521-6.

9. Reinhardt JD, Post MWM, Fekete C, Trezzini B, Brinkhof MWG. Labour market integration of people with disabilities: results from the Swiss Spinal Cord Cohort Study. PLoS ONE. 2016;11: $\mathrm{e} 0166955$.

10. Kieser U, Senn J. Invalidität: Alles über Renten, Rechte und Versicherungen, 4. Zürich: vollst. überarb. und aktualisierte Aufl. edn Beobachter; 2011.

11. Bräunlich Keller I. Arbeitsrecht. Zürich: Beobachter-Edition; 2017.

12. Ziegler R. Die berufliche Situation vor und nach Eintritt einer Querschnittlähmung. DMGP Informationsblatt 2005; February 15-18.

13. Chan SK, Man DW. Barriers to returning to work for people with spinal cord injuries: a focus group study. Work. 2005;25:325-32.

14. Chapin MH, Kewman DG. Factors affecting employment following spinal cord injury: a qualitative study. Rehabil Psychol. $2001 ; 46: 400-16$. 
15. Ramakrishnan K, Mazlan M, Julia PE, Abdul Latif L. Return to work after spinal cord injury: factors related to time to first job. Spinal Cord. 2011;49:924-7.

16. Krause JS, Terza JV, Saunders LL, Dismuke CE. Delayed entry into employment after spinal cord injury: factors related to time to first job. Spinal Cord. 2010;48:487-91.

17. Krause JS. Years to employment after spinal cord injury. Arch Phys Med Rehabil. 2003;84:1282-9.

18. Schönherr MC, Groothoff JW, Mulder GA, Eisma WH. Vocational perspectives after spinal cord injury. Clin Rehabil. 2005;19:200-8.

19. Krause JS, Terza JV, Dismuke CE. Factors associated with labor force participation after spinal cord injury. J Vocat Rehabil. 2010;33:89-99.

20. Meade MA, Barrett K, Ellenbogen PS, Jackson MN. Work intensity and variations in health and personal characteristics of individuals with spinal cord injury (SCI). J Vocat Rehabil. 2006;25:13-9.

21. Murphy GC, Young AE. Employment participation following spinal cord injury: relation to selected participant demographic, injury and psychological characteristics. Disabil Rehabil. 2005;27:1297-306.

22. Krause JS, Terza JV, Erten M, Focht KL, Dismuke CE. Prediction of postinjury employment and percentage of time worked after spinal cord injury. Arch Phys Med Rehabil. 2012;93:373-5.

23. Brinkhof MW, Fekete C, Chamberlain JD, Post MW, Gemperli A. Swiss national community survey on functioning after spinal cord injury: Protocol, characteristics of participants and determinants of non-response. J Rehabil Med. 2016;48: $120-30$.

24. WHOQOL Group. The World Health Organization Quality of Life Assessment (WHOQOL): development and general psychometric properties. Social Sci Med. 1998;46:1569-85.

25. FORS. Swiss household panel, wave 14 (individual questionnaire). Lausanne: FORS; 2012.

26. ILO. International Standard Classification of Occupations 2008 (ISCO-08). Geneva: International Labour Organization; 2008.
27. Cleves MA, Gutierrez RG, Gould WW, Marchenko YV. An introduction to survival analysis using Stata. College Station, TX: Rev. edn Stata Press; 2010.

28. Baum CF. Stata tip 63: Modeling proportions. Stata J. 2008;8:299-303.

29. Von Hippel PT. Regression with missing Ys: an improved strategy for analyzing multiply imputed data. Sociol Methodol. 2007;37:83-117.

30. Tomassen PC, Post MW, van Asbeck FW. Return to work after spinal cord injury. Spinal Cord. 2000;38:51-5.

31. Krause JS. Employment after spinal cord injury. Arch Phys Med Rehabil. 1992;73:163-9.

32. BFS. Taschenstatistik der Schweiz 2017. Bern: Bundesamt für Statistik; 2017.

33. Krause JS, Terza JV, Dismuke C. Earnings among people with spinal cord injury. Arch Phys Med Rehabil. 2008;89:1474-81.

34. Jain NB, Sullivan M, Kazis LE, Tun CG, Garshick E. Factors associated with health-related quality of life in chronic spinal cord injury. Am J Phys Med Rehabil. 2007;86:387-96.

35. Tonack M, Hitzig SL, Craven BC, Campbell KA, Boschen KA, McGillivray CF. Predicting life satisfaction after spinal cord injury in a Canadian sample. Spinal Cord. 2008;46:380-5.

36. Marti A, Escorpizo R, Schwegler U, Staubli S, Trezzini B. Employment pathways of individuals with spinal cord injury living in Switzerland: a qualitative study. Work. 2017;58:99-110.

37. Kristof-Brown AL, Zimmerman RD, Johnson EC. Consequences of individuals' fit at work: a meta-analysis of person-job, personorganization, person-group, and person-supervisor fit. Pers Psychol. 2005;58:281-342.

38. Nützi M, Trezzini B, Medici L, Schwegler U. Job matching: an interdisciplinary scoping study with implications for vocational rehabilitation counseling. Rehabil Psychol. 2017;62:45-68.

39. O'Hare MA, Murphy G. Withdrawal from employment gained post-SCI: precipitating factors. Aust J Rehabil Couns. 2015;21:91-107.

40. Murphy G, Brown D, Athanasou J, Foreman P, Young A. Labour force participation and employment among a sample of Australian patients with a spinal cord injury. Spinal Cord. 1997;35:238-44. 